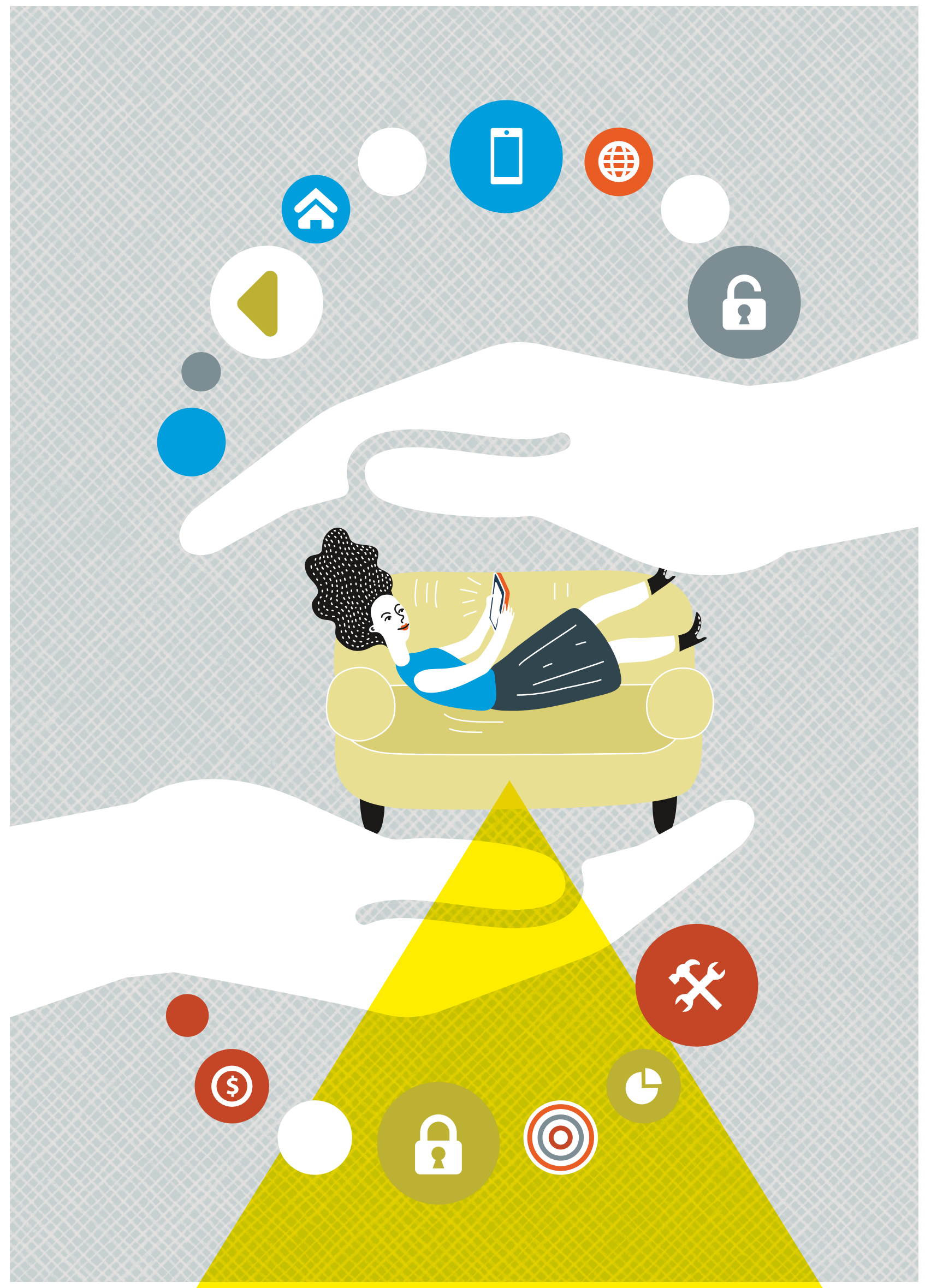




\title{
Connecting the World and Reinventing Customer Centricity
}

\author{
Rudolf Aunkofer
}

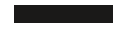 \\ KEYWORDS \\ Customer Centricity, IoT, \\ Technical Consumer Goods, Smart Technology, \\ Customer Journey, Touchpoints \\ THE AUTHOR \\ Rudolf Aunkofer \\ Business Partner Information Technology, GfK \\ rudi.aunkofer@gfk.com \\ Director und Professor Institute of Information \\ \& Supply Chain Management, \\ University of Applied Management, \\ Ismaning, Germany \\ rudolf.aunkofer@fham.de
}

Smart technology - a revolution in buying behavior /// Smart refrigerator or not? At first glance, the difference really isn't that great. In the future, technical consumer goods will mostly remain long-term investments with product life cycles of several years. Yet, the way in which we select, buy and use technology, will be revolutionized in the next five to ten years. That's the conclusion of an expert survey the GfK Verein carried out in cooperation with the ISCM Institute at the University for Applied Management. The Internet of Things (IOT) and increasing digitalization enable providers to better understand customers for one thing, and, for another, to personalize technical products and services. Even today, new technologies such as artificial intelligence, virtual reality, robotics or voice and gesture control offer a glimpse of what could become reality very soon. The relationships manufacturers and retailers have with customers will radically and permanently change and become more interactive. Therefore, it is necessary to rethink ways of creating emotional and positive shopping and product experiences in an loT context.

The customer journey reinvented - a relationship revoIution /// Even modern versions of the digital-analog customer journey continue to be rooted more in the thinking of the twentieth century than in the digital opportunities of the twenty-first: a purchasing decision as a consciously managed process following a funnel logic and characterized by individual touchpoints in its individual phases (see Figure 1). This view implicitly assumes that consumers lack and need information which is not readily available. Additionally, the market situation is judged to lack transparency, and time budgets and information processing capacities are assumed to be limited. 


\section{FIGURE 1:}

\section{Customer journey - learned assumptions versus new reality}

- Individual, widely conscious process

- classic „funnel“ with several phases(awareness, consideration, preference, purchase, after sales cycle)

- Customer loyalty as a consequence of process reiteration

- Typical touch-points in each step of the process
- Entry into the process at any point

$\rightarrow$ faster purchase decision

- Exit from the process at any point $\rightarrow$ prolongated purchase decision

- Skipping of single phases $\rightarrow$ immediate purchase

- Skipping of the whole process $\rightarrow$ thabitualized purchase

Management of lifelong customer relationships that are more spontaneous,

Management of single, well-matched touchpoints along the customer journey. individualized, situations-specific, interactive and, hence, more difficult to plan.

loT ecosystem
Connected products and the ubiquitous availability of networks and cloud-services create new conditions. Everybody can now be reached anytime, generating diverse data that can easily and quickly be accessed. This leads to a market transparency that has never existed before and also massively affects the customer journey. Better information, education and knowledge cause more transparency and make the whole journey more flexible, more individual and significantly shorter. It happens in multiple, partially automatized and is less predictable for manufacturers and retailers. The classical customer journey with its touchpoints is transformed into a lifelong, interactive customer relationship within an loT-based product-service-ecosystem (Figure 1).

\section{Ecosystems instead of physical product features}

/// Additionally, for technical consumer goods such as television sets, smartphones, computers or even appliances, physical product features are becoming less important than digital, software-driven qualities. Considering the high market satu- ration, long usage cycles and over-fulfillment of requirements, many product features are often rated as less critical than in the past. - Who actually uses all of the programs of a smart washing machine? Who uses all of the recording functions of smart TVs or all cleaning modes of a smart toothbrush? - The industry speaks of a commoditization of markets - products are experienced as functionally interchangeable.

For many users, customer satisfaction results from simplicity, service and convenience over the entire life-cycle. Important aspects are user-friendliness, integration into a comprehensive service ecosystem and a smart and connected serviceinterface with remote access. Flexible apps that can be updated easily make it possible to adapt digital products to customer needs quickly and in almost any way. Log-in effects are generated, which result in platform-based replacements and follow-up purchases of products from the same manufacturer or other network partners. 
FIGURE 2:

\section{Share of smart products in the total volume of product areas for which a smart product version exists (individual European countries)}

$12 \%$

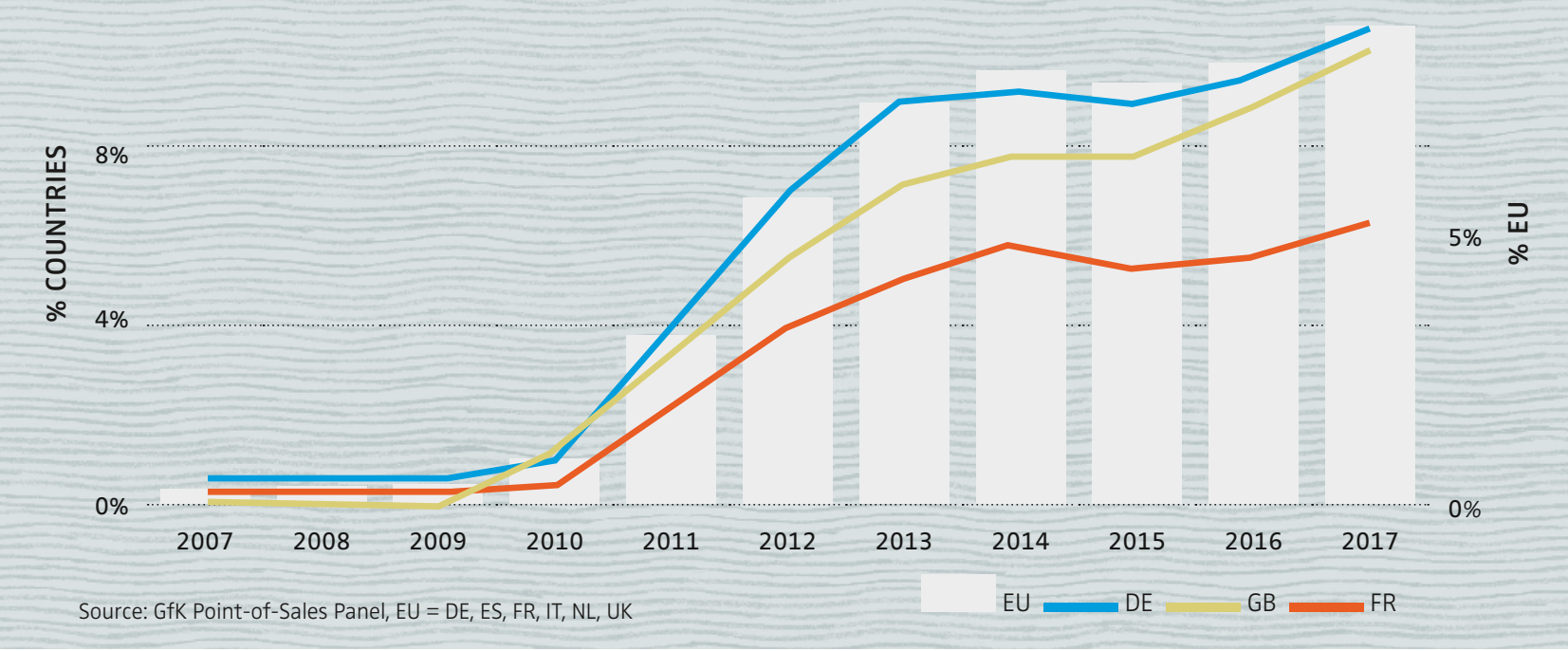

IoT - Much room to grow /// At this point, most households are already connected. In Germany, around 91\% of households have internet access, around $89 \%$ have a computer and around $76 \%$ own a smartphone, and other Western European markets are similar. The infrastructure for exchanging digital data with manufacturers and services partners is thus available.

By contrast, the demand for connected products is comparably low and differs from country to country (see Figure 2). It is obvious that consumers do not necessarily prefer smart product solutions. After quick growth initially, the share of smart products has been increasing at a much slower rate since 2014 as more and more products with smart versions have been launched and are starting from scratch. The benefits of "smart" are still too vague for many consumers and a willingness to try out smart solutions is often limited to innovators and early adopters. Many manufacturers are still focusing on non-smart products at more affordable prices.
The adoption rate of the average consumer is thus slow and often dominated by pricing. The advantages of platform- and ecosystem-effects have not yet been fully thought through by many manufacturers or adequately communicated to retailers and customers.

Therefore, consumer adoption of smart products is the true challenge for the Internet of Things. The high market saturation for technical consumer goods results in new purchases occurring primarily to replace defective or outdated products. In Germany, for instance, $97 \%$ of households owned a washing machine in 2017; for TV sets, it was 96\%; for dishwashers $72 \%$ and for electrical toothbrushes $59 \%$. The numbers are similar in scale all over Western Europe.

For the smart versions of these products, however, adoption varies significantly. According to a GfK consumer panel, after seven years of smart TVs, the rate is at around 68\%; after five years of smart washing machines and toothbrushes, it is only 
FIGURE 3:

\section{Growth in demand and development in prices for smart product categories over one year}

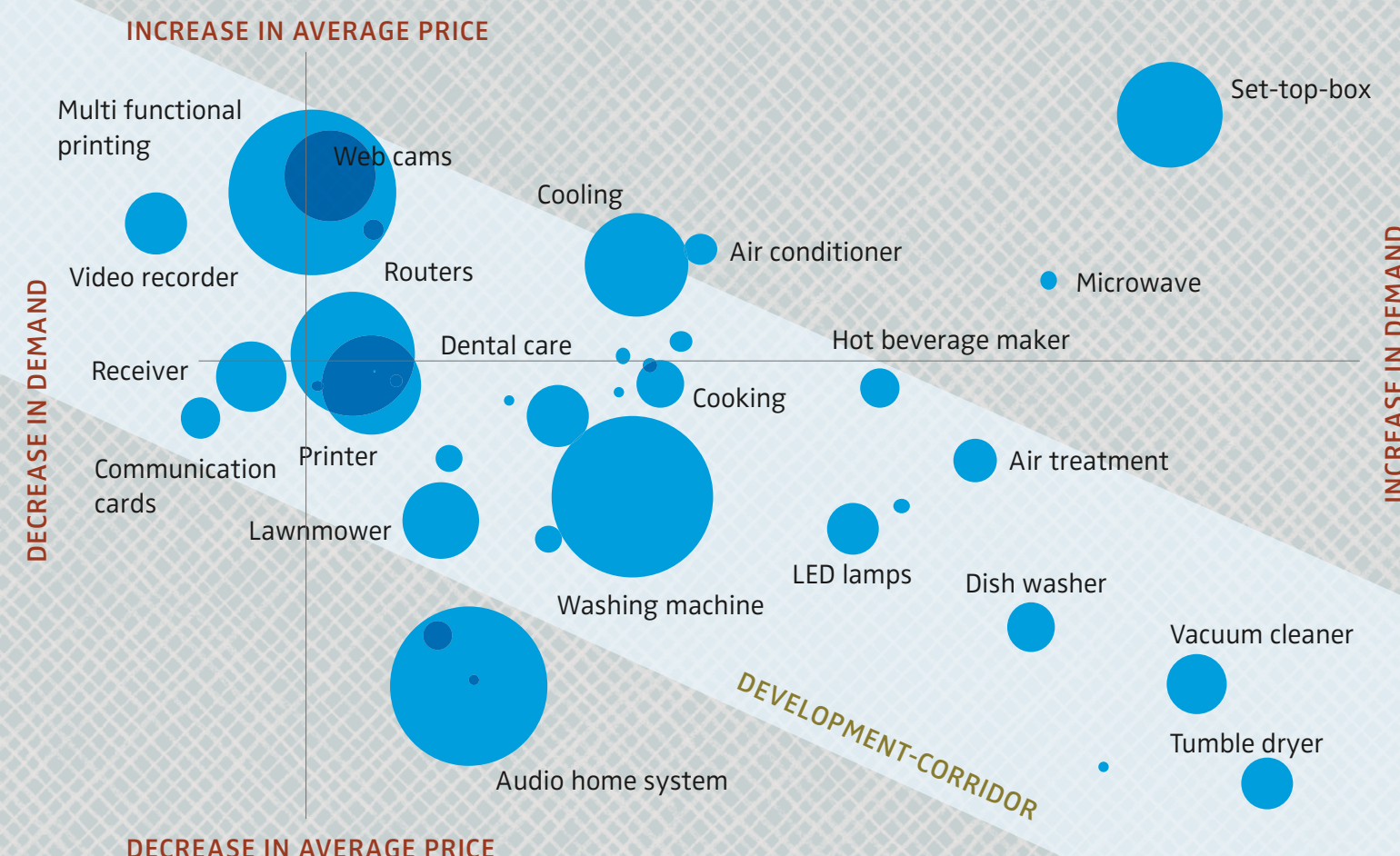

DECREASE IN AVERAGE PRICE

Source: GfK Point-of-Sales Panel, Development Trends 2017 vs. 2016

at around 2-3\% and after three years of smart dishwashers, it is still under $1 \%$. This shows that the rate of adoption of IoT-products strongly depends on the assessment of their concrete benefits and varies significantly for different types of devices. The product's image and visibility as well as the product policies of the manufacturers are also relevant. The high adoption rate of smart TVs is likely a consequence of many manufacturers' policies to integrate smart features as a standard into higher priced models. A portfolio analysis of large European countries (Germany, France, the United Kingdom, Italy, Spain, the Netherlands) clearly shows that of the 40 smart product categories registering a positive increase in demand in 2017, 58\% made price concessions with decreasing average prices. This is a clear indication that just being "smart" is not enough to justify a permanent price premium.
Customer centricity 4.0: Redesigning user value /// For many product categories, the IoT is thus not going to take off until providers and retailers succeed in getting at what their customers really want. For one thing, they need to better understand individual usage behavior, and for another, there is a need to better personalize products and services, creating emotional and situation-specific customer experiences. Expanding the ability of digital products to communicate with each other, to record and analyze usage behavior and to implement concrete product improvements will be decisive.

Individual customer centricity is already apparent today in digital marketing and the design of digital product components, e.g. in the multitude of available apps or in services that can be booked individually. Convenience, like being able 
to return products or obtaining refunds for e-books that a customer does not like, or simplicity, like being able to cancel a contract at any time, will become new standards. Consumers are taking these "digital conveniences" and their continual improvement as a given for future product use. This is the only way to position products in a high price category and to ensure noticeable and tangible benefits for customers. Longer usage cycles for technical products require a focus on practical and concrete advantages from loT-integration. If customers see a real value - for example, in better service and more tailored and flexible performance - smart products will replace classical products in the next five to ten years. Industry and retail should consider the following recommendations to convince consumers of the benefits of the Internet of Things:

$>$ Offer situation-and user-specific product information /// Customers are literally "always on". The classical consumer journey occurs individually and in many different ways, making it complex and only partially predictable. It is necessary to use all relevant marketing, sales and communications channels to personalize interactions with customers. Consumers naturally expect to be addressed individually and no longer as an anonymous member of a group. Individual product recommendations during online shopping are a first step in this direction.

> Personalized and automated customer service /// The IoT will become the central instrument for collecting customer and usage data. Providers should customize their marketing and services based on this data. Customers should be personally and directly addressed, and they should be able to select tailor-made customer service. This includes digital bookmarks across devices or dash buttons that activate the entire supply chain with a single click. Smart washing machines, for instance, should be able to automatically reorder the necessary laundry detergent based on individual usage.

$>$ Build trust in brands /// Consumers will nevertheless only use automated services if they trust the respective provider. A brand enabling consistently positive customer experiences leads to investment security, which reduces the perceived risk of a purchase. Brand credibility and positive experiences are decisive success factors when usage cycles are long. Especially in the market of technical consumer goods, these factors create brand loyalty. Modular and flexible services like provided by most telecommuni- cations or pay-TV brands, lead to loyal consumers within specific product and service ecosystem. The (seemingly) individual need fulfillment creates trust in brands.

$>$ Ensure convenience and simplicity /// Simplicity and convenience in using products and services as well as easy-to-understand contracts will become prerequisites. Consumers desire direct, quick, simple, intuitive and holistic experiences in each specific situation. Lights that automatically turn on or off when someone is present, or that dim according to the time of day or day of the week, are initial steps in the right direction. Energy management such as running dishwashers and other appliances according to the output of solar panels is another application. Voice recognition and control can be combined with artificial intelligence to enable a more intuitive interaction with technical goods, requiring less technical expertise.

The loT offers an unforeseeable range of new options. The challenge lies less in obtaining data about customers and their behavior than in selecting and extracting the most informative user data in a smart way. Only by analyzing the relevant data will it be possible to gain information about actual customer needs in a connected world. This will be a precondition for successfully developing products with longterm relevance and for creating new customer centricity.

I.

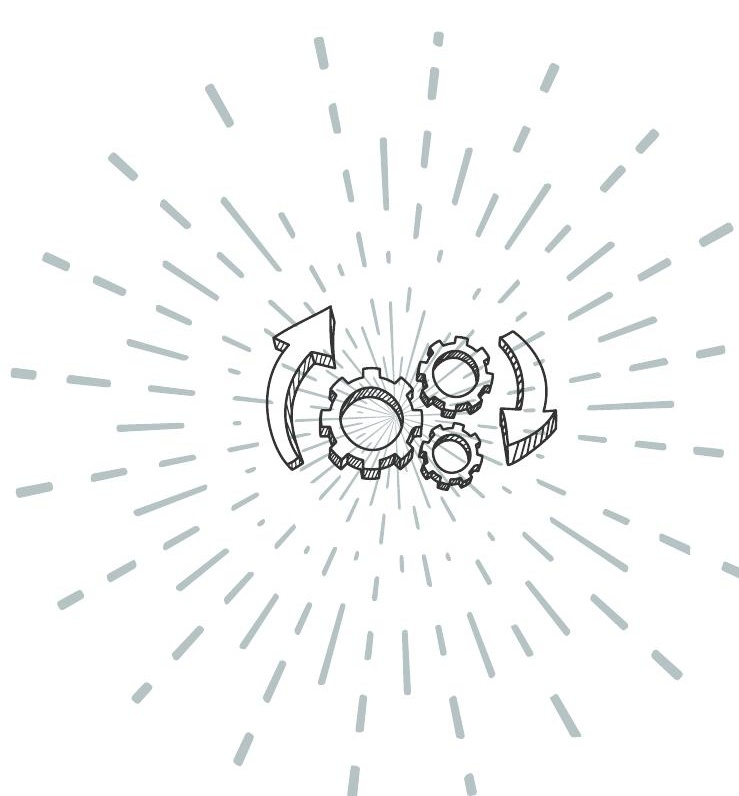

